\title{
AÇÃO COMUNICATIVA, DIREITO E ENFRENTAMENTO DA VIOLENNCIA
}

\author{
Elza Machado de MELO* \\ Victor Hugo de MELO** \\ Mirian Conceição Moreira de ALCÂNTARA** \\ Sônia Parreiras MAIA ${ }^{* * *}$
}

RESUMO: Este artigo propõe apresentar, inicialmente, a Teoria da Ação Comunicativa de Jurgen Habermas, para em seguida descrever como o autor, a partir dela, formula uma Teoria do Direito e da Democracia. Tomando por referência esse arcabouço teórico, construído a partir dos principais conceitos da teoria, a saber, ação comunicativa, discurso, mundo da vida e sistema, será analisada a violência disseminada nas sociedades contemporâneas, utilizando especialmente a tese da colonização do mundo da vida pelo sistema. Ora, se essa teoria é trazida como explicação para a violência, ela ilumina também possíveis caminhos e estratégias da sua superação, que são, por sua vez, adotados na elaboração e execução de vários projetos do Núcleo de Promoção de Saúde de Paz, ensejando profícuo entrelaçamento de teoria e prática. Finalmente, para concluir, breves consideraçôes sobre a Terapia Comunitária Integrativa (TCI) serão apresentadas, na tentativa de estabelecer nexos entre elas e os conceitos apresentados anteriormente.

\footnotetext{
* UFMG - Universidade Federal de Minas Gerais. Faculdade Medicina - Coordenadora e docente permanente do Programa de Pós-Graduaçăo de Promoçăo de Saúde e Prevenção da Violência. Belo Horizonte - MG - Brasil. 31270-901 - elzammelo@hotmail.com

** UFMG - Universidade Federal de Minas Gerais. Faculdade Medicina - Docente permanente do Programa de Pós-Graduação de Promoção de Saúde e Prevenção da Violência. Belo Horizonte - MG - Brasil.31270-901 - victormelo@terra.com.br

*** Mestre em Promoção de Saúde e Prevenção da Violência. UFMG - Universidade Federal de Minas Gerais. Faculdade Medicina - Pós-Graduação de Promoçâo de Saúde e Prevenção da Violência. Belo Horizonte - MG - Brasil. 31270-901. Profissional da Rede Municipal de Saúde de Belo Horizonte. Terapeuta comunitária - miriannalcantara@pbh.gov.br
}

**** Enfermeira e terapeuta comunitária. Prefeitura Municipal de Brumadinho. Brumadinho - MG - Brasil. 35460-000 - jhgmaia@hotmail.com 


\section{Elza Machado de Melo, Victor Hugo de Melo, Mirian Conceição Moreira de Alcântara e Sônia Parreiras Maia}

PALAVRAS-CHAVE: Ação comunicativa. Democracia. Direito. Terapia Comunitária Integrativa.

\section{Açáo comunicativa}

A ação comunicativa é a interação mediada pela linguagem, na qual os atores se entendem uns com os outros para coordenar suas açóes. Em outras palavras, é ação desenvolvida por, pelo menos, 2 sujeitos ou mais e que tem exclusivamente o entendimento linguístico como mecanismo coordenador da ação (HABERMAS, 1996). O entendimento linguístico é o acordo racional entre sujeitos participantes da interação ou o processo racional de produção desse acordo, mediado pela linguagem no seu uso comunicativo cotidiano, a fala. O que está em jogo nesse acordo é exclusivamente a força das razóes que os sujeitos se atribuem reciprocamente, não envolvendo qualquer outra coerção. Trata-se, portanto, de uma relação de intersubjetividade, como tal, isenta de violência (HABERMAS, 1987).

Ao utilizarem o entendimento linguístico para mediar sua interaçáo, os atores se entendem uns com os outros e, dessa forma, harmonizam e integram seus interesses e planos de ação e, assim, conseguem agir no mundo, de forma cooperativa (HABERMAS, 1990). Diferentemente da ação comunicativa, na ação estratégica os atores procuram, cada um, atingir seu interesse particular e, em vez de se entenderem uns com os outros para organizarem uma ação cooperativa, eles tomam uns aos outros como variáveis que devem ser levadas em consideração nos seus respectivos cálculos, agindo instrumental ou estrategicamente, para atingir o fim desejado. Reproduzem, portanto, entre si, a relação que se dá entre sujeito e objeto. Por isso, esse tipo da ação comporta sempre um ingrediente de coerção, de violência (HABERMAS, 1987). Como se vê, ação comunicativa e ação estratégica são radicalmente distintas uma da outra, a primeira se orienta pelo entendimento, a segunda pelo êxito. Elas incorporam racionalidades diferentes: enquanto a ação estratégica envolve a racionalidade instrumental, dada pela adequação entre meios e fins, a ação comunicativa, ao contrário, incorpora a racionalidade comunicativa, subjacente ao entendimento linguístico - que envolve a expectativa recíproca de reconhecimento, segundo a qual, todos os envolvidos se atribuem reciprocamente razóes para dizerem o que dizem e fazerem o que fazem e são, aos olhos uns dos outros, capazes de, se necessário for, apresentá-las e com elas fundamentar seus pontos de vista, seus interesses, sua vontade (HABERMAS, 1989a). 
O conceito de ação comunicativa envolve também a sua forma reflexiva, o discurso, forma rigorosa e exigente de comunicação que tem lugar quando, havendo questionamentos profundos acerca dos saberes ligados às falas dos participantes, a interação é interrompida, permanecendo, apenas e exclusivamente, a argumentação, aberta a todos e em condições de igualdade, com a garantia de que, enquanto houver discordância, a discussão persistirá e de que só valerá a força do melhor argumento. Tal processo de argumentaçáa se inicia na prática comunicativa cotidiana - aqui e agora - mas pode prosseguir, superar o contexto, ganhar fronteiras, abrir-se a todos os envolvidos e atingir universalidade (HABERMAS, 1991, 1989b).

Ação comunicativa e discurso se assentam sobre a mesma base que é o entendimento linguístico. Ação comunicativa e discurso constituem a base da teoria de direito e democracia proposta por Habermas, tendo por ponto de partida o princípio do discurso, segundo o qual "[...] só podem reclamar validez as normas que encontrem (ou possam encontrar) o assentimento de todos os concernidos enquanto participantes de um discurso prático.", (HABERMAS, 1989b, p.89) que, como princípio moral, se entrelaça ao direito de modo que o direito institucionaliza o princípio moral, representado pelos processos discursivos formadores de opinião e de vontade coletiva e, esses processos, por sua vez e ao mesmo tempo, legitimam o direito. Desse entrelaçamento nascem o direito legítimo e o princípio da democracia (HABERMAS, 1996). Essa tese forte, dialeticamente construída, segundo a qual direito e democracia são co-originários - logo, um não existe sem o outro - se expressa como institucionalização dos processos discursivos de formação da opiniấo e da vontade, condiçáo necessária para o exercício da autonomia, em que todos os atores envolvidos se constituem como autores do direito frente ao qual são destinatários (HABERMAS, 1996). Os direitos sociais, sem exceção, são desdobramentos dessa premissa.

\section{Ação comunicativa, mundo da vida e sistema}

A açáo comunicativa/discurso ocorre sempre dentro de um mundo da vida, que é o conjunto de saberes pré-teóricos, implícitos, e que, compartilhados pelos participantes da interação e colocados às suas "costas", formam o horizonte da situação que vivenciam e garantem os recursos utilizados por eles para que se entendam uns com os outros numa dada situação e desenvolvam suas interaçôes. A ação comunicativa, por sua vez, é o meio pelo qual o mundo da vida se reproduz. Os participantes da 


\section{Elza Machado de Melo, Victor Hugo de Melo,

ação comunicativa, ao se entenderem entre si, reproduzem e renovam a cultura; ao coordenarem linguisticamente a açáo, produzem e reproduzem lealdades; e a criança, ao participar das interaçóes, incorpora valores sociais e desenvolve habilidades. Portanto, a ação comunicativa tem as funçôes de, no que diz respeito à cultura, realizar a reprodução cultural; no que diz respeito a sociedade, garante integração social e solidariedade e, no que diz respeito à personalidade, promove os processos de socialização, que formam sujeitos capazes de fala e ação. Nessa relaçáo circular entre mundo da vida e ação comunicativa, vemos que os sujeitos são ao mesmo tempo produto e produtores do contexto onde estão inseridos (HABERMAS, 1987, 1989a). Nessa relação, são produzidos saberes, sociabilidade e sujeitos.

$\mathrm{O}$ mundo da vida, no entanto, não esgota todos os aspectos da sociedade, que também precisa da reprodução material, desempenhada por outro âmbito da sociedade, a saber, o sistema cujo mecanismo de regulação não é mais a integração social e sim a autorregulação acima e independente de todos, dada pelo efeito do agregado das conseqüências das açóes de cada ator social isolado (HABERMAS, 1975, 1987). Mundo da vida é o mundo sociocultural, constituído pela esfera pública e pela vida privada; sistema é Estado e Economia. A evolução social se faz, entâo, como racionalização do mundo da vida e como aumento de complexidade sistêmica e, nas sociedades atuais do capitalismo tardio, ela acaba por levar ao que Habermas denomina colonização do mundo da vida pelo sistema: os processos comunicativos que coordenam a açáo dos atores e que geram vontade coletiva e garantem a reproduçáo do mundo da vida são substituídos por mecanismos sistêmicos de controle, o poder e o dinheiro. Rompe-se o jogo dialético, onde indivíduo e sociedade se constituem reciprocamente, trazendo agora para o âmbito do mundo da vida o controle sistêmico, inaugurando uma nova forma de dominação muito mais indevassável do que as ideologias tradicionais, que comprometem os processos comunicativos cotidianos pelos quais os atores sociais participantes das interaçóes se reconhecem reciprocamente como sujeitos, tendo como resultado o individualismo possessivo; comprometem os processos pelos quais esses atores produzem opiniáo e vontade coletiva, geram poder comunicativo e interferem, como cidadãos na tomada de decisão, na construção do direito e na formulação de políticas públicas, levando, portanto. à perda, da sua autonomia política. Por fim, comprometem a reprodução simbólica do mundo da vida, surgindo, entáo, as patologias sistemicamente induzidas, a saber, perda de sentido, anomia, psicopatologias e alienaçóes, com 
todas as suas consequências (HABERMAS, 1987). Isso é violência que abre espaço para violência.

\section{Enfrentamento da violência}

Se como foi dito, a raiz do problema está no comprometimento dos processos comunicativos mediadores das interaçôes, logo, na compressão da ação comunicativa, nada mais lógico do que centrar a abordagem e a prevenção da violência na retomada desse tipo de interação. Por isso, no nosso entendimento, combater a violência antes de tudo é recuperar em cada espaço, no cotidiano, essa competência que nos dá a todos a condiçấo de sujeitos, a fala. Obviamente que não se pretende resolver de vez a violência, ao contrário, o pressuposto central é o de que soluçóes para a violência envolvem a responsabilidade de todos os cidadáos, um fazer concreto aqui e agora, inspirado na certeza de que tudo começa quando pelo menos dois sujeitos se encontram e se dispóem a agir cooperativamente - como diz Habermas, "[...] qualquer encontro de atores que se atribuem, reciprocamente, liberdades comunicativas, abre-se como espaço público linguisticamente constituído." (HABERMAS, 1996). Se a colonização do mundo da vida é violência, então, quando pessoas se encontram e se dispóem a agir cooperativamente, elas já estão prevenindo a violência. Quando apresentamos esta postulação, não estamos pressupondo um mundo da vida isento de múltiplas violências. Ao contrário, pensamos que, de fato, ele comporta desigualdades, injustiças e exclusão, mas, por outro lado, é passível de transformação, posta ao alcance dos atores que interagem, porque quando os fragmentos do acervo de saberes passam pelo "torvelinho" da ação comunicativa, eles podem ser questionados em discursos teóricos e práticos, mudando dessa forma, a cultura; porque novos vínculos, novas identidades e novas percepçóes podem ser constituídas, gerando opiniôes e vontades coletivas que podem modificar as relaçóes entre sistema e mundo da vida (HABERMAS, 1987). Essa é a orientação seguida, cotidianamente, em nosso trabalho em todos os projetos que desenvolvemos cuja metodologia consiste, fundamentalmente, da formulação de estratégias de criação de espaços que propiciem o diálogo e de estabelecimento de relaçóes pautadas no reconhecimento recíproco, como forma essencial de formação da opiniáo e da vontade coletiva. Sáo encontros que geram, inspiram, estimulam e multiplicam novos encontros, sucessivamente, ininterruptamente, em cadeia, formando redes interativas, que podem ser cada vez mais amplas e abrangentes, formando saberes, práticas e sujeitos coletivos. Assim, se constituem os 
nossos projetos: Frutos do Morro, Núcleo de Promoção de Saúde e Paz, Rede Saúde e Paz, Projeto Para Elas, Programa de Transferências de Tecnologias.

Também não é outra senão esta, a orientação do setor saúde quando incorpora a violência como um problema que lhe diz respeito, sendo explícito, na sua abordagem, o reconhecimento de que não pode se restringir, em hipótese alguma, aos danos já causados, as palavras de ordem sendo sempre promoçáo de saúde e construçáo da paz, como estratégias centrais de prevençáo da violência, orientaçáo que se ajusta perfeitamente àquela inspirada na Teoria da Açáo Comunicativa de Habermas e, por consequência, à necessidade de superação da colonização do mundo da vida e recuperaçáo dos elementos de participaçáo dialógica que essa colonização corrompe, permitindo dessa forma, a conquista de direitos. Este arcabouço participação/direito, não por acaso, é também o pilar constitutivo da promoção de saúde (WHO, 2009; CONFERENCIA INTERNACIONAL SOBRE A PROMOÇÃO DA SAÚDE, 1986; SAPAG; KAWACHI, 2007; AYRES, 2007). Assim é que surge o Programa de Pós-Graduação Mestrado Profissional de Promoçáo de Saúde e Prevenção da Violência, cujas premissas - e não apenas elas, mas também, os métodos de ensino e pesquisa geradores de contribuiçôes para a formulação de políticas - se assentam firmemente na construção de vínculos e de solidariedade entre todos os participantes e todos os cidadãos que queiram participar. Venham eles de onde vierem, encontrarão sempre coraçóes, mentes e portas abertas para recebê-los, do modo como deveria ser todo espaço público.

\section{O que é a Terapia Comunitária Integrativa (TCI)?}

Hoje a TCI é uma prática que ressalta a importância do processo de reconhecimento das competências locais das comunidades, enfatiza a necessidade de ressignificar conteúdos e práticas que resultem em mudança de postura, por meio do desenvolvimento da capacidade crítica dos sujeitos, da ampliação da percepçáo dos problemas e das possibilidades de resolução a partir destas competências. Fomenta, portanto, a construçáo das redes sociais que se nutrem desse processo e ao mesmo o fortalece, rumo à transformação da realidade.

A prática foi validada durante a IV Conferência Nacional de Saúde Mental - Intersetorial, realizada entre 27 de junho e primeiro de julho de 2010 em Brasília, aprovando a TCI como política pública prioritária nacional. 
A TCI tem sua origem no estado do Ceará e vem ganhando seguidores em diversos estados brasileiros e em países da América Latina (México, Uruguai e Argentina) e Europa (França, Suíça, Portugal). No ano de 2008, o Ministério da Saúde incorporou a prática como uma estratégia de promoção da saúde e de prevenção do adoecimento, para os serviços da rede básica de saúde, especificamente para a estratégia de saúde da família. A cada dia a TCI vem agregando profissionais de diversas formaçóes, usuários, familiares convidados e lideranças comunitárias, em processos de mobilização para enfrentamento de problemas, formando uma rede invisível de apoio.

A Terapia Comunitária e suas açôes complementares incentivam a co-responsabilidade na busca de novas alternativas existenciais e promove mudanças fundamentadas em três atitudes básicas:

1. Acolhimento respeitoso;

2. Formaçáo de vínculos; $\mathrm{e}$

3. Empoderamento das pessoas.

A terapia comunitária vem se inserindo na área da saúde congregando os mais diferentes atores sociais de diferentes classes sociais, profissōes, raças, credos, partidos englobando agentes comunitários de saúde, profissionais da ESF, assistentes sociais, psicólogos, fisioterapeutas, sociólogos, numa prática de ação conjunta e complementar. O Projeto de Implantaçáo da Terapia Comunitária e Açóes Complementares na Rede de Assistência à Saúde do SUS pretendem desenvolver nos profissionais da área da saúde, por meios de módulos teóricos e práticos, as competências necessárias para promover as redes de apoio social na atenção primária da saúde. A proposta prevê capacitar os profissionais da rede básica no sentido de prepará-los para lidar com os sofrimentos e demandas psicossociais, de forma a ampliar a resolutividade desse nível de atenção. (BRASIL, 2009).

Barreto (2008) ressalta que a TCI se baseia nos seguintes pressupostos fundamentais: toda pessoa, qualquer que seja sua condição socioeconômica ou cultural, possui recursos e saberes úteis aos outros, ou seja, competências que provêm das dificuldades superadas e dos recursos culturais experimentados e aprendidos ao longo da vida. A prática é pautada pela ética das relaçóes a serviço dos valores da vida, igualdade, justiça e cidadania. Tem por objetivo reforçar a rede de apoio, criar espaços de inclusão e valorizaçáo da diversidade, resgatando a herança cultural e a historia pessoal do sujeito. 


\section{Elza Machado de Melo, Victor Hugo de Melo, Mirian Conceição Moreira de Alcântara e Sônia Parreiras Maia}

A TCI está essencialmente fundamentada em cinco pilares fundamentais e norteadores: Teoria Sistêmica, Teoria da Comunicação, Antropologia Cultural, Pedagogia de Paulo Freire e Resiliência, que fundamentam a premissa de que os sujeitos devem ser conhecidos e compreendidos de forma indissociável do seu contexto e de que as relaçóes estabelecidas entre ele sejam mediadas pela linguagem (PADILHA; OLIVEIRA, 2012). Tal premissa já aproxima inequivocamente a TCI da proposta da ação comunicativa, isto é, da interação entre sujeitos linguisticamente mediada.

A Teoria Sistêmica enfatiza a questão de que as crises e os problemas individuais só podem ser resolvidos se percebidos dentro de um contexto maior, que inclui o biológico, o psicológico e a sociedade. A Teoria da Comunicação aponta para o fato de que a comunicação é o elemento que une os indivíduos no seu grupo social. Ressalta que todo comportamento é comunicação e que ela pode acontecer de forma verbal e não-verbal, indo além das palavras. A Antropologia Cultural chama a atenção para as diferentes culturas onde as pessoas estáo inseridas, sendo um elemento de referência fundamental na identidade pessoal e grupal. E é a partir dessa referência que os indivíduos se afirmam, se aceitam e assumem sua identidade. A pedagogia Freiriana parte do princípio de que todos nós temos conteúdos e experiências a trocar, aprendendo e ensinando em sinergia constante e a resiliência consiste na superaçáo de uma dor profunda transformada em sabedoria para lidar com esse tipo de sofrimento (FERREIRA FILHA; CARVALHO, 2010).

Tal proposta de abordar e acolher o sofrimento humano gerado pelos problemas sociais da modernidade, estimulando o fortalecimento de redes comunitárias, prevenindo a evolução de problemas familiares e sociais por meio da valorização da herança cultural, do resgate das origens e das raízes históricas do povo, constitui procedimento terapêutico de caráter preventivo em saúde.

\section{Terapia Comunitária Integrativa no enfrentamento da violência}

No campo da saúde, sobretudo no Brasil, as práticas assistenciais têm dificuldades em trabalhar as questóes que não se apresentam como doença e se limitam ao tratamento das conseqüências, sobretudo aos danos físicos e psicológicos, intensificando desse modo a ideia de que seria essa a face do problema que caberia ao setor.

Sabe- se, no entanto que, o desafio para os serviços de saúde é exatamente criar açôes capazes de impactar positivamente a saúde da popula- 
ção, considerando-se a realidade sanitária contemporânea com alta prevalência de doenças crônicas, violências, uso abusivo de álcool e outras drogas, desigualdades sociais, dentre outros.

Em nossa experiência dentro do Mestrado Profissional de Promoção de Saúde e Prevenção da Violência, tivemos oportunidade de atuar na abordagem da violência por meio da TCI, especialmente, dentro do Projeto Para Elas, por Elas, por Eles, por Nós, que é um projeto de âmbito nacional de Atenção à Saúde Integral da Mulher, elaborado pelo Núcleo de Promoção de Saúde e Paz do Departamento de Medicina e Preventiva e Social/FM/UFMG, em parceria com o Ministério da saúde. Uma das metas do projeto é a construção de redes para o enfrentamento da violência contra mulheres do campo e da floresta e das águas, nos 10 municípios brasileiros e suas microrregióes, definidos no conjunto, como territórios de cidadania, selecionados no Fórum Nacional de Enfrentamento da Violência contra Mulher, para efetivar uma das propostas do Plano Nacional de Políticas para as Mulheres.

As populaçôes do campo e da floresta e das águas são constituídas por povos e comunidades que têm seus modos de vida, produção e reprodução sociais relacionados predominantemente com a terra. Neste contexto estão "[...] os camponeses, sejam eles agricultores familiares, trabalhadores rurais assentados ou acampados, assalariados e temporários que residam ou não no campo. Além das comunidades tradicionais, como as ribeirinhas, quilombolas e as que habitam ou usam reservas extrativistas em áreas florestais ou aquáticas e ainda as populaçôes atingidas por barragens, entre outras [...]" (BRASIL, 2011a, p.1).

A Política Nacional de Saúde Integral da População do Campo Floresta (BRASIL, 2011a), fruto do reconhecimento das condiçóes e dos determinantes sociais do campo e da floresta no processo saúde/doença dessas populaçóes, é composta por objetivos, diretrizes e estratégias que exigem responsabilidades da gestáo estadual, municipal e sociedade civil, voltadas para a melhoria das condiçóes de saúde desse grupo populacional, sendo, portanto, política transversal com o grande desafio de materializar esses propósitos, seja concentrando esforços na atenção e no cuidado em saúde, seja priorizando a redução das desigualdades de acesso às açôes e aos serviços do SUS para essas populaçôes ou ainda facilitando o acesso aos serviços de saúde, geralmente, marcado por grandes dificuldades, agravadas pelas grandes distâncias e pela dispersáo populacional. Segundo a Pesquisa Nacional por Amostra de Domicílios (IBGE, 2007), as condiçôes de saúde da população rural são determinadas por especificidades relacionadas ao ritmo de trabalho sazonal, aos processos de mobi- 


\section{Elza Machado de Melo, Victor Hugo de Melo, Mirian Conceição Moreira de Alcântara e Sônia Parreiras Maia}

lidade espacial dos acampamentos e assentamentos, à baixa escolaridade, à pobreza, às situaçóes de violência e às relaçóes de trabalho e de gênero que contribuem para tornar os trabalhadores rurais mais vulneráveis às enfermidades.

Apesar dos reconhecidos e organizados movimentos sociais, dentre os quais a Marcha das Margaridas, que têm lutado pelos direitos das mulheres do campo e da floresta (BRASIL, 2011b) a divisão sexual do trabalho continua sendo um dos principais problemas geradores da desigualdade de gênero fortemente marcada no meio rural.

A articulação das açôes profissionais, por meio da sua conexão pela TCI, favoreceu, além da interação entre eles, a discussão sobre a violência. A metodologia da TCI foi aplicada para 110 profissionais e gestores da rede de serviços de atenção à mulher em situação de violência em várias regiốes brasileiras, por meio de vivências e rodas de TCI, com o a utilização do mote violência. Oficinas com a metodologia da TCI foram realizadas em Belo Horizonte - MG, Augustinópolis - TO, São Mateus - ES, Goiânia -GO, Cruzeiro do Sul - AC.

A Terapia Comunitária Integrativa (TCI) promoveu, por meio de rodas que propiciam o diálogo e apontam novos caminhos para a produção da saúde como uma estratégia metodológica para o trabalho coletivo com participação democrática, a prática calcada na ação reflexiva e na partilha de experiências; valorizou as histórias de vidas dos participantes e o resgate da sua identidade e contribuiu para a restauração da autoestima e da confiança em si. Favoreceu a inclusão da diversidade e procurou contribuir para o empoderamento dos sujeitos no enfrentamento dos determinantes do processo saúde-doença e para a consequente melhoria da qualidade de vida de indivíduos e coletivos.

As rodas de TCI concretizaram relações intersubjetivas entre os participantes e a entrada no mundo da vida, uns dos outros. O problema distante passou ser real, a experiência vivida ganhou forma e passou a ser reconhecida reciprocamente entre sujeitos, a ação comunicativa, como proposta por Habermas, mostrou-se, nesses momentos, aos olhos de todos, como corporificação das interaçóes mediadas pela linguagem.

O maior êxito da roda de TCI se deu em dois momentos, o da contextualização e problematização, pois ambos privilegiam o diálogo e a fala e, desta forma o vivido pode ser dito. O vivido se tornou compartilhável, ainda que tal linguagem pertença a um dos indivíduos, por certo momento. O relato, legitimado sem julgamento e, livre de coerçáo, foi expresso no seu contexto intersubjetivo e social. Quando o direito de falar é negado ou a comunicação está rompida, temos, então, estabelecidas as relaçôes 
de poder, os discursos competentes, a violência onde o objetivo é convencer ou anular o outro. Cessa-se a liberdade de comunicação, as possibilidades de resposta e de ação, de autonomia e liberdade nas relaçôes. Ao contrário, na interação comunicacional que acontece na TCI, é possível ver o outro como sujeito, valorizar suas histórias de vida, e por isso, ela pode ser instrumento de proteção das relaçôes interpessoais pelo resgate da autoestima - nesse espaço, acontece a ampliação da percepçáo dos problemas e as possibilidades de respostas, a geraçáo do poder compartilhado. E é essa força ativa da fala, como forma de comunicar e agir que convoca o outro e a si mesmo a repensarem posturas e modos de viver.

Por meio da TCI, problemas vivenciados assemelhados váo se identificando e sua superação tem início no momento em que deixam de ser isolados, para ganhar a dimensão coletiva, garantindo, nesta perspectiva, a construção de pensamentos positivos para as pessoas e delas com o mundo; o empoderamento de cada um no encontro com o outro e a produção de soluções compartilhadas. Isso é perfeitamente harmônico com a definição de ação comunicativa, especialmente, quando se trata da liberdade de comunicação, das possibilidades de resposta e de ação, de autonomia e liberdade nas relaçóes. Trata-se, portanto, da possibilidade de mudança de saberes, valores culturais e práticas, promovendo a prevenção da violência, rumo a uma cultura de paz.

\section{COMUNICATIVE ACTION, LAW AND VIOLENCE COPING}

ABSTRACT: This article proposes to present initially the Communicative Action Theory of Jurgen Habermas, to then describe how the author, as it formulates a Theory of Law and Democracy. With reference to this theoretical framework, built on the main concepts of the theory, namely communicative action, speech, life world and system, widespread violence will be analyzed in contemporary societies, especially using the thesis of the colonization of the life world by system. But if this theory is brought as an explanation for violence, it illuminates also possible ways and strategies to overcome them, which are, in turn, adopted in the preparation and implementation of various health promotion core projects of Peace, occasioning fruitful interweaving of theory and practice. Finally, in conclusion, brief consideration of the Integrative Community Therapy (TCI) will be presented in an attempt to establish links between them and the concepts presented above.

KEYWORDS: Communicative action. Democracy. Law. Integrative Community Therapy. Violence. 


\section{REFERÊNCIAS}

AYRES, J. R. C. M. Uma concepção hermenêutica de saúde. Physis: Revista de Saúde Coletiva, Rio de Janeiro, v.17, n.1, p.43-62, 2007.

BARRETO, A. P. Terapia comunitária: passo a passo. 4.ed.rev.ampl. Fortaleza: Gráfica LCR, 2008.

BRASIL. Ministério da Saúde. Institui, no âmbito do Sistema Único de Saúde (SUS), a Política Nacional de Saúde Integral das Populaçóes do Campo e da Floresta (PNSIPCF). Portaria no 2.866, de 2 de dezembro de 2011a. Disponível em: <http://www.saude.go.gov.br/public/media/EU6s WLAaw55isy/21131001103041610209.pdf_>. Acesso em: 5 jan. 2014

BRASIL. Ministério da Saúde. Plano operativo da Política Nacional de Saúde Integral das populaçóes do campo e da floresta: 2012-2015. Brasília, 2011b. Disponível em: <http://www.contag.org.br/imagens/ fpoli769tica-nacional-de-sau769de-das-populac807o771 es-campo-efloresta.pdf>. Acesso em: 6 jul. de 2015.

BRASIL. Ministério da Saúde. Departamento de Atenção Primária. Saúde da Família. O Projeto da Terapia Comunitária na Atençáo Primária, 2009. Disponível em: <http://dtr2004.saude.gov.br/dab/ terapia_comunitaria.php>. Acesso em: 20 nov. 2011.

CONFERENNCIA INTERNACIONAL SOBRE A PROMOÇÃO DA SAÚDE, 1., 1986, Otawa. Carta de Otawa. Otawa, 1986. Disponível em: $<$ https://pt.wikipedia.org/wiki/Carta_de_Ottawa>. Acesso em: 16 maio 2014.

FERREIRA FILHA, M. O.; CARVALHO, M. A. P. A Terapia Comunitária em um Centro de Atençáo Psicossocial: (des)atando pontos relevantes. Revista Gaúcha de Enfermagem, Porto Alegre, v.31, n.2, p.232-239, jun. 2010. Disponível em: <http://www.scielo.br/scielo. php?script=sci_arttext\&pid=S1983-14472010000200005 >. Acesso em: 10 jan. 2011.

HABERMAS, J. Between facts and norms: contributions to a discourse theory of law and democracy. Cambridge: The MIT Press, 1996.

HABERMAS, J. Escritos sobre moralidad y eticidad. Barcelona: Paidós, 1991. 
HABERMAS, J. Pensamento pós-metafísico. Rio de Janeiro: Tempo Brasileiro, 1990.

HABERMAS, J. Teoria de la Accíon Comunicativa: complementos y estudios prévios. Madrid: Ed. Cátedra, 1989a.

HABERMAS, J. Consciência moral e agir comunicativo. Rio de Janeiro: Tempo Brasileiro, 1989b.

HABERMAS, J. Teoria de la acción comunicativa: racionalidad de la acción y racionalización social. Trad. Manuel Jiménez Redondo. Madrid: Taurus, 1987.

HABERMAS, J. Legitimation crisis. Boston: Beacon Press, 1975.

IBGE. Pesquisa Nacional de Amostras por Domicílio 2007: PNAD 2007. Disponível em: <http:/www.ibge.gov.br/home/estatistica/populacao/ trabalhoerendimento/pnad2007/default.shtm>. Acesso em: 20 nov. 2011.

PADILHA, C. S.; OLIVEIRA, W. F. Terapia comunitária: prática relatada pelos profissionais da rede SUS de Santa Catarina, Brasil. Interface: Comunicação Saúde Educação, Botucatu, v.16, n.43, p.1069-1083, out./ dez. 2012.

SAPAG, J. C.; KAWACHI, I. Capital social y promoción de la salud en América Latina. Revista de Saúde Pública, São Paulo, v.41, n.1, p.139149, feb. 2007.

WORLD HEALTH ORGANIZATION [WHO]. Milestones Health Promotion. Geneva, 2009. Disponível em: <http://www.who.int/health promotion/Milestones_Health_Promotion_05022010.pdf $>$. Acesso em: 20 nov. 2011. 
